\title{
SYSTEMATIC REVIEW
}

\section{Diagnostic accuracy of ${ }^{18}$ F-FDG PET/CT for detection of peritoneal carcinomatosis; a systematic review and meta-analysis}

\author{
1,2 SEONG-JANG KIM, MD,PhD and ${ }^{3}$ SANG-WOO LEE, MD,PhD \\ ${ }^{1}$ Department of Nuclear Medicine, Pusan National University Yangsan Hospital, Yangsan, Republic of Korea \\ ${ }^{2}$ BioMedical Research Institute for Convergence of Biomedical Science and Technology, Pusan National University Yangsan Hospital, \\ Yangsan, Republic of Korea \\ ${ }^{3}$ Department of Nuclear Medicine, Kyungpook National University Medical Center and School of Medicine, Daegu, Republic of Korea
}

Address correspondence to: Dr Seong-Jang Kim

E-mail: growthkim@daum.net

Objective: The current review aimed to investigate the performance of the diagnostic accuracy of ${ }^{18} \mathrm{~F}$ - fludeoxyglucose positron emission tomography/CT (PET/CT) in detecting peritoneal carcinomatosis (PC) through a systematic review and meta-analysis.

Methods: The MEDLINE via PubMed and EMBASE from the earliest available date of indexing to 31 March 2017, were searched for studies evaluating the diagnostic performance of ${ }^{18} \mathrm{~F}-\mathrm{FDG}$ PET/CT in detecting PC. We evaluated the pooled sensitivities and specificities across included studies, calculated positive and negative likelihood ratios (LR+ and LR-), and plotted summary receiver operating characteristic curves. Deek's funnel plot asymmetry tests were used to assess the possible underlying publication bias.

Results: The current meta-analysis demonstrated no significant publication bias $(p=0.21$ ). Across 14 studies (671 patients), the overall sensitivity of ${ }^{18} \mathrm{~F}$-FDG PET/ $\mathrm{CT}$ was $0.87[95 \% \mathrm{Cl}(0.77-0.93)]$ with heterogeneity

\section{INTRODUCTION}

Peritoneal carcinomatosis (PC) is a common evolution of many abdominal or extra-abdominal malignancies and considered as a terminal condition with a poor outcome, as most patients die within 6 months. ${ }^{1}$ The primary treatment of PC include total peritonectomy and resection of involved tissue with intraperitoneal chemotherapy as an approach with curative intention. ${ }^{2-4}$ The development of locoregional therapy has changed dramatically the approach to some clinical entities that evolve with peritoneal diffusion, namely pseudomyxoma peritonei, colon cancer and peritoneal mesothelioma, according to Phase II and III clinical trials. ${ }^{5,6}$ The extent and volume of the PC is one of the most important prognostic factors and the pre-operative detection and quantification of PC is essential for the planning $\left(x^{2}=94.2, p=0.00\right)$ and a pooled specificity of 0.92 [95\% Cl; $(0.89-0.94)]$ with heterogeneity $\left(\chi^{2}=20.6\right.$, $p=0.08)$. LR syntheses gave an overall LR+ of $10.4[95 \%$ $\mathrm{Cl}$ (7.5-14.5)] and LR- of 0.14 [95\% Cl (0.08-0.26)]. The pooled diagnostic odds ratio was 73 [95\% Cl (34-159)]. In univariate meta-regression analysis, publication year and cohort homogeneity were the potent sources of heterogeneity. However, in multivariate meta-regression, no definite variable was the source of the study heterogeneity.

Conclusion: ${ }^{18}$ F-FDG PET/CT demonstrated good sensitivity and specificity for the detection of PC. Further large multicentre studies would be necessary to substantiate the diagnostic accuracy of ${ }^{18} \mathrm{~F}$-FDG PET/CT for the diagnosis of $P C$ in various cancers.

Advances in knowledge: ${ }^{18}$ F-FDG PET/CT showed good diagnostic performance in the evaluation of $P C$ and could provide additional information for that purpose in various cancers. the treatment algorithm, especially for the design of the surgical approach. The gold standard for quantification of the PC is surgical exploration and the laparoscopy is a less invasive procedure than laparotomy. ${ }^{7}$

Many imaging techniques have been used for the detection of and pre-operative evaluation of patients with PC, including CT, MRI and ${ }^{18} \mathrm{~F}$-fludeoxyglucose (FDG) positron emission tomography/CT (PET/CT) ${ }^{8-12}$ Recently, the diagnostic accuracy of CT for the detection of PC and the detection of peritoneal implants has improved owing to the introduction of multidetector row CT. ${ }^{12-14}$ However, the efficacy of CT for the detection of PC could be compromised by the small size of tumour implants. PET with ${ }^{18} \mathrm{~F}$ FDG PET/CT has remarkably improved the management 
of cancer patients and is increasingly applied in the staging and restaging of various cancers. ${ }^{15,16}$ The combination of ${ }^{18}$ F-FDG PET/CT allows an improvement in the anatomical localization of intra- and extrapelvic structures and their relationship with ${ }^{18} \mathrm{~F}$ FDG uptake can provide more reliable data regarding the nature of the pathological findings.

Some previous studies have evaluated the diagnostic performance of ${ }^{18} \mathrm{~F}-\mathrm{FDG}$ PET/CT in the evaluation of PC, reporting different values of sensitivity and specificity. The purpose of our study is to meta-analyse the published data on the diagnostic performance of ${ }^{18} \mathrm{~F}$-FDG PET/CT in the evaluation of PC, in order to provide more evidence-based data and to address further studies in PC.

\section{METHODS AND MATERIALS}

Data sources and search strategy

This systematic review and meta-analysis was carried out using the PRISMA 2009 guidelines ${ }^{17}$ and we conducted electronic English-language literature searches of MEDLINE via PubMed and Embase from the earliest available date of indexing to 31 March 2017. We also hand-searched the reference lists of identified publications for additional studies. We used a search algorithm based on a combination of terms: (1) "PET" OR "positron emission tomography"; and (2) "peritoneum" OR "peritoneal" AND "carcinoma" OR "carcinomatosis".

The study protocol was prepared and followed to conduct this project and provided to give readers additional information about the current work (, Supplementary material available online)

\section{Study selection}

The inclusion criteria for relevant studies were as follows: wholebody ${ }^{18} \mathrm{~F}$-FDG PET/CT had been used to identify and characterize the suspected PC; sufficient data to reassess sensitivity and specificity of ${ }^{18} \mathrm{~F}$-FDG PET/CT in detecting the PC or absolute numbers of true-positive (TP), true-negative (TN), false-positive (FP) and false-negative (FN) data had been presented; and no data overlap.

Studies were excluded if ${ }^{18}$ F-FDG PET/CT had been used for prediction of prognosis or if fewer than five patients had been included. In addition, duplicate studies were excluded. Also the publications such as review articles, case reports, conference abstracts and letters were excluded because of the lack of original data for calculation of sensitivity and specificity. Two researchers (Kim SJ, Lee SW) independently reviewed titles and abstracts of the retrieved articles, applying the above-mentioned selection criteria. Articles were rejected if clearly ineligible. The same two researchers then independently evaluated the full-text version of the included articles to determine their eligibility for inclusion.

\section{Data extraction and quality assessment}

Information about basic study (authors, publication year, country of study conducted), study design (prospective or retrospective), patients' characteristics (number of patients, mean age, gender) and technical aspects (injected dose of ${ }^{18}$ FDG etc) were collected.

Each study was analysed to calculate the number of TP, TN, FP and FN findings of ${ }^{18} \mathrm{~F}-\mathrm{FDG}$ PET/CT in patients with $\mathrm{PC}$ or suspicious PC, according to the reference standard. Only studies providing such complete information were finally included in the meta-analysis.

The overall quality of the included studies in this review was critically appraised by two authors independently, based on 15-item modified Quality Assessment of Diagnostic Accuracy Studies. ${ }^{18}$ Disagreement between the two authors was resolved by discussion.

\section{Data synthesis and analysis}

All data from each eligible study were extracted. The pooled sensitivity and specificity, and diagnostic odds ratios (DORs), are reported as estimates with $95 \%$ confidence intervals (CIs). A DOR can be calculated as the ratio of the odds of positivity in a disease state relative to the odds of positivity in the non-disease state, with higher values indicating better discriminatory test performance. ${ }^{19}$ The statistical heterogeneity between studies for sensitivity and specificity was assessed using $I^{2}$ and the Cochrane $Q$ test in terms of the random-effects analysis. ${ }^{20}$ Possible publication bias was investigated using the effective sample size funnel plot and associated regression test of asymmetry described by Deeks and colleagues. ${ }^{21}$ We used the bivariate random-effects model for analysis and pooling of the diagnostic performance measures across studies. ${ }^{22,23}$ The bivariate model estimates pairs of logit transformed sensitivity and specificity from studies, incorporating the correlation that might exist between sensitivity and specificity. We also used the model to create hierarchical summary receiver operating characteristic curves and to estimate the area under the curve. ${ }^{24}$ Also we performed meta-regression to identify potential sources of bias. ${ }^{25}$ Pooled estimates were also calculated for subgroups of studies that were defined according to specific study designs. Two-sided $p \leq 0.05$ was considered statistically significant. Statistical analyses were performed with commercial software programs (STATA, v. 13.1; StataCorp LP, College Station, TX).

\section{RESULTS}

\section{Literature search and selection of studies}

After the comprehensive computerized search was performed and references lists were extensively cross-checked, we identified 168 articles from PubMed, 130 articles from Embase. Of which, 157 articles (non-English article 19, Conference abstract 44 , not in the field of interest of this review 94) were excluded after reviewing the title and abstract. Remaining 50 full text articles were assessed for eligibility and 36 articles were excluded owing to insufficient data for the calculation of sensitivity and specificity of ${ }^{18} \mathrm{~F}$-FDG PET/CT for the detection of PC. Finally, 14 articles $^{26-39}$ were selected and were eligible for the systematic review and meta-analysis. The characteristics of the included studies are presented in Table 1 . The flow of study selection in the systematic review is shown in Figure 1. 
Table 1. Characteristics of the included studies

\begin{tabular}{|c|c|c|c|c|c|c|c|c|c|c|}
\hline Authors & Year & Country & $\begin{array}{c}\text { Imaging } \\
\text { device }\end{array}$ & $\begin{array}{l}\text { Image } \\
\text { analysis }\end{array}$ & $\begin{array}{l}\text { Patient } \\
\text { number }\end{array}$ & Age & $\begin{array}{l}\text { Male/ } \\
\text { female }\end{array}$ & $\begin{array}{c}\text { 18F-FDG } \\
\text { dose }\end{array}$ & $\begin{array}{l}\text { Primary } \\
\text { cancer }\end{array}$ & $\begin{array}{l}\text { Study } \\
\text { design }\end{array}$ \\
\hline Pfannenberg C & 2009 & Germany & $\mathrm{PET} / \mathrm{CT}$ & PB & 22 & 58 & $8 / 14$ & $\begin{array}{c}350 \sim 450 \\
\mathrm{MBq}\end{array}$ & $\begin{array}{l}\text { GIC (13), OC } \\
(8), \text { MST (1) }\end{array}$ & $\mathrm{R}$ \\
\hline Suzuki A & 2004 & Japan & $\mathrm{PET}+\mathrm{CT}$ & PB & 35 & NR & NR & $\begin{array}{c}200 \sim 370 \\
\mathrm{MBq}\end{array}$ & $\begin{array}{l}\text { OC (9), CC } \\
(5), \text { EC (6), } \\
\text { CeC (4), PC } \\
\text { (3), BDC } \\
\text { (3), SC (3), } \\
\text { HCC (1) }\end{array}$ & $\mathrm{R}$ \\
\hline Dirisamer A & 2009 & Austria & $\mathrm{PET} / \mathrm{CT}$ & $\mathrm{PB}$ & 62 & 62 & $13 / 49$ & $370 \mathrm{MBq}$ & $\begin{array}{c}\text { OC (32), CRC } \\
\text { (16), EC } \\
(9), \text { SC } \\
(4), \mathrm{CeC}(1)\end{array}$ & $\mathrm{R}$ \\
\hline Satoh Y & 2011 & Japan & $\mathrm{PET} / \mathrm{CT}$ & $\mathrm{PB}$ & 107 & 61.1 & $51 / 56$ & $3 \mathrm{MBq} \mathrm{kg}^{-1}$ & $\begin{array}{c}\text { GIC (45), GUC } \\
(23)\end{array}$ & $\mathrm{R}$ \\
\hline Berthelot C & 2011 & France & $\mathrm{PET} / \mathrm{CT}$ & PB & 28 & 59 & $7 / 21$ & $5 \mathrm{MBq} \mathrm{kg}^{-1}$ & $\begin{array}{c}\text { CRC (17), OC } \\
\text { (9), SC } \\
\text { (1), P-MST (1) }\end{array}$ & $\mathrm{R}$ \\
\hline Panagiotidis E & 2012 & Greece & $\mathrm{PET} / \mathrm{CT}$ & PB & 73 & 62 & $30 / 43$ & $5 \mathrm{MBq} \mathrm{kg}^{-1}$ & $\begin{array}{c}\text { CRC (32), OC } \\
\text { (18), SC } \\
\text { (7), PC } \\
\text { (7), CeC } \\
\text { (4), EC (3), DC } \\
\text { (1), SBC (1) }\end{array}$ & $\mathrm{P}$ \\
\hline Soussan M (a) & 2012 & France & $\mathrm{PET} / \mathrm{CT}$ & PB & 30 & 63 & $19 / 11$ & $\begin{array}{c}3 \sim 3.5 \\
\text { MBq kg-1 }\end{array}$ & $\begin{array}{c}\text { CRC (12), PC } \\
\text { (8), SC } \\
\text { (5), ESC } \\
(3), \text { SBC (2) }\end{array}$ & $\mathrm{R}$ \\
\hline Klumpp BD & 2012 & Germany & $\mathrm{PET} / \mathrm{CT}$ & LB & 15 & 57.9 & $4 / 11$ & $350 \mathrm{MBq}$ & $\begin{array}{l}\text { OC (6), CRC } \\
\text { (3), AC } \\
\text { (5), MST (1) }\end{array}$ & $\mathrm{R}$ \\
\hline Sanli Y & 2012 & Turkey & $\mathrm{PET} / \mathrm{CT}$ & PB & 47 & 57.5 & $0 / 47$ & $\begin{array}{c}370 \sim 550 \\
\mathrm{MBq}\end{array}$ & OC (47) & $\mathrm{R}$ \\
\hline Filippi L & 2013 & Italy & $\mathrm{PET} / \mathrm{CT}$ & $\mathrm{PB}$ & 15 & 64.2 & $10 / 5$ & $\begin{array}{c}3.7 \\
\mathrm{MBq} \mathrm{kg}^{-1}\end{array}$ & CRC (15) & $\mathrm{R}$ \\
\hline Kim HW & 2013 & Korea & $\mathrm{PET} / \mathrm{CT}$ & $\mathrm{PB}$ & 46 & 54 & $0 / 46$ & $350 \mathrm{MBq}$ & OC (46) & $\mathrm{R}$ \\
\hline Rubini G & 2014 & Italy & $\mathrm{PET} / \mathrm{CT}$ & $\mathrm{PB}$ & 79 & 59.8 & $0 / 79$ & $\begin{array}{c}4.6 \\
\mathrm{MBq} \mathrm{kg}^{-1} \\
\end{array}$ & OC (79) & $\mathrm{R}$ \\
\hline Liberale G & 2017 & Belgium & $\mathrm{PET} / \mathrm{CT}$ & PB & 52 & 57.7 & $23 / 29$ & $\begin{array}{c}250 \sim 350 \\
\mathrm{MBq}\end{array}$ & CRC (52) & $\mathrm{R}$ \\
\hline $\begin{array}{l}\text { Lopez- } \\
\text { Lopez V }\end{array}$ & 2016 & Spain & $\mathrm{PET} / \mathrm{CT}$ & PB & 59 & 54 & $0 / 59$ & $370 \mathrm{MBq}$ & OC (59) & $\mathrm{R}$ \\
\hline
\end{tabular}

AC, appendix cancer; BDC, bile duct cancer; CC, colon cancer; CeC, cervical cancer; CRC, colorectal cancer; DC, duodenal cancer; EC, endometrial cancer; ESC, oesophageal cancer; GIC, gastrointestinal cancer; GUC, genitourinary cancer; HCC, hepatocellular cancer; LB, lesionbased; MST, mesothelioma; NR, not reported; OC, ovarian cancer; P, prospective; PB, patient-based; PC, pancreatic cancer; PET, positron emission tomography; P-MST, peritoneal mesothelioma; R, retrospective; SBC, small bowel cancer; SC; stomach cancer.

\section{Study description, quality, publication bias}

We conducted all analyses based on per-patient and per-lesion data analysis. Among those 14 studies included in the current review, one study conducted both of lesion-based and patient-based analysis of ${ }^{18} \mathrm{~F}$-FDG PET/CT. ${ }^{32}$ One study conducted only lesion-based analysis. ${ }^{33}$ There was a total of 671 patients in the included studies, and the age ranged from 16 to 95 years. A total of 165 patients were male, and 506 patients were female. The one study did not report the number of male and female patients in their population. ${ }^{27}$ Of all 14 studies, 13 studies ${ }^{26-30,32-39}$ enrolled patients retrospectively; 1 study $^{31}$ enrolled patients prospectively. The study cohort was homogenous in seven studies ${ }^{32,34-39}$ and heterogeneous in seven studies. ${ }^{26-31,33}$ One study assessed the diagnostic performance of delayed ${ }^{18} \mathrm{~F}$-FDG PET/CT image. ${ }^{35}$ The principal characteristics of the 14 studies included in the meta-analysis are included in Table 1. To assess a possible publication bias, Deeks's funnel plot asymmetry tests (Figure 2) were designed. The non-significant slope indicates that no significant bias was found. The $p$ value was 0.21 . 
Figure 1. Flow chart of the search for eligible studies on the diagnostic performance of ${ }^{18} \mathrm{~F}$-FDG PET/CT for detection of PC. ${ }^{18}$ F-FDG, fludeoxyglucose; PC, peritoneal carcinomatosis; PET, positron emission tomography.

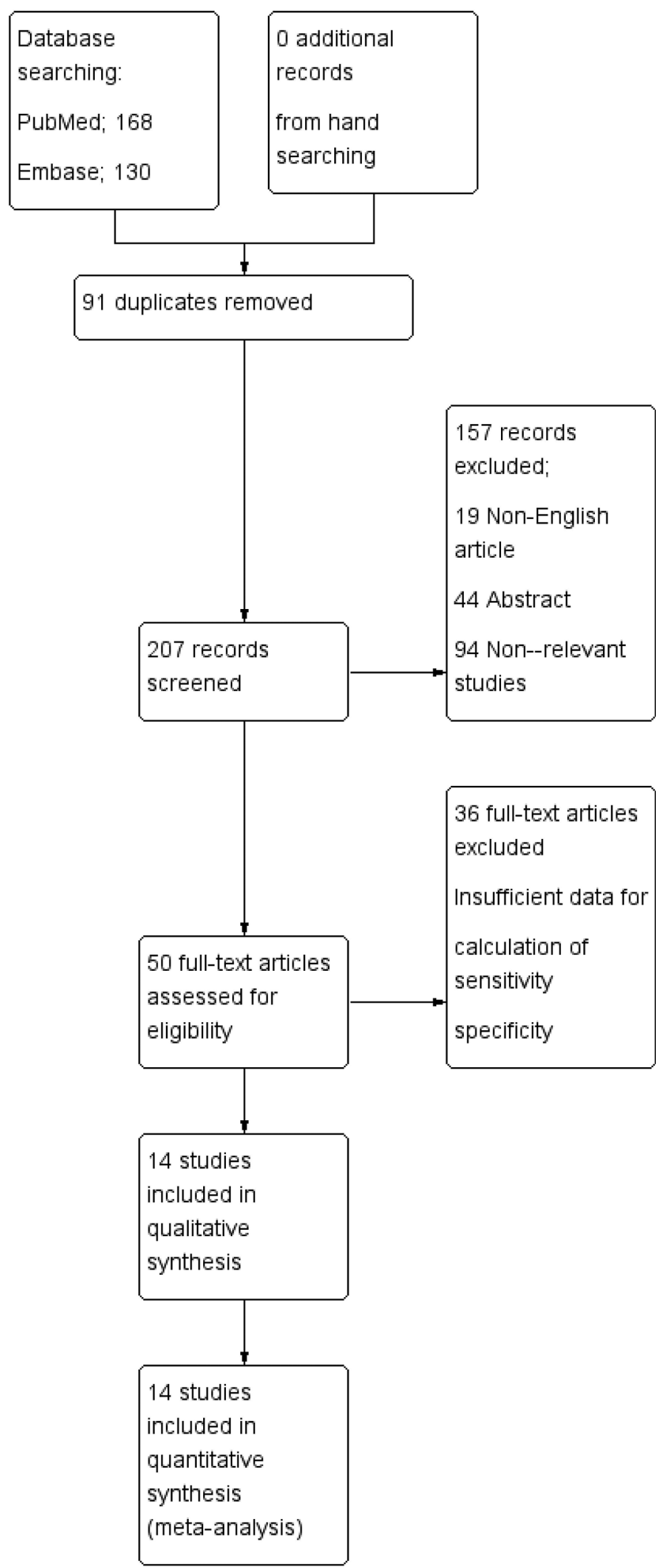

Methodological quality assessment

Figure 3 shows the risk of bias and applicability concerns summary and overall, the quality of the included studies was
Figure 2. Results of Deeks's funnel plot of asymmetry test for publication bias. Non-significant slope indicates that no significant bias was found. ESS; effective sample size.

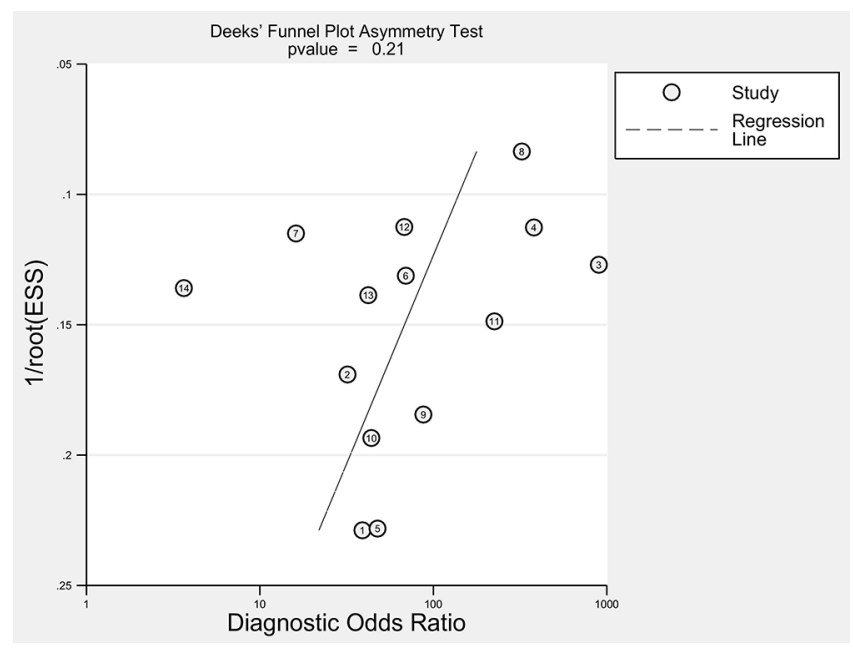

deemed satisfactory.

Diagnostic accuracy of ${ }^{18} \mathrm{~F}$-FDG PET/CT

The diagnostic performance results of ${ }^{18} \mathrm{~F}$-FDG PET/CT in the 14 included studies in the meta-analysis are presented in Figures 4 and 5. The pooled sensitivity for ${ }^{18} \mathrm{~F}-\mathrm{FDG}$ PET/CT was 0.87 [95\% CI $(0.77-0.93)]$ with heterogeneity $\left(\chi^{2}=94.2, p=0.00\right)$ and a

Figure 3. Risk of bias and applicability concerns summary.

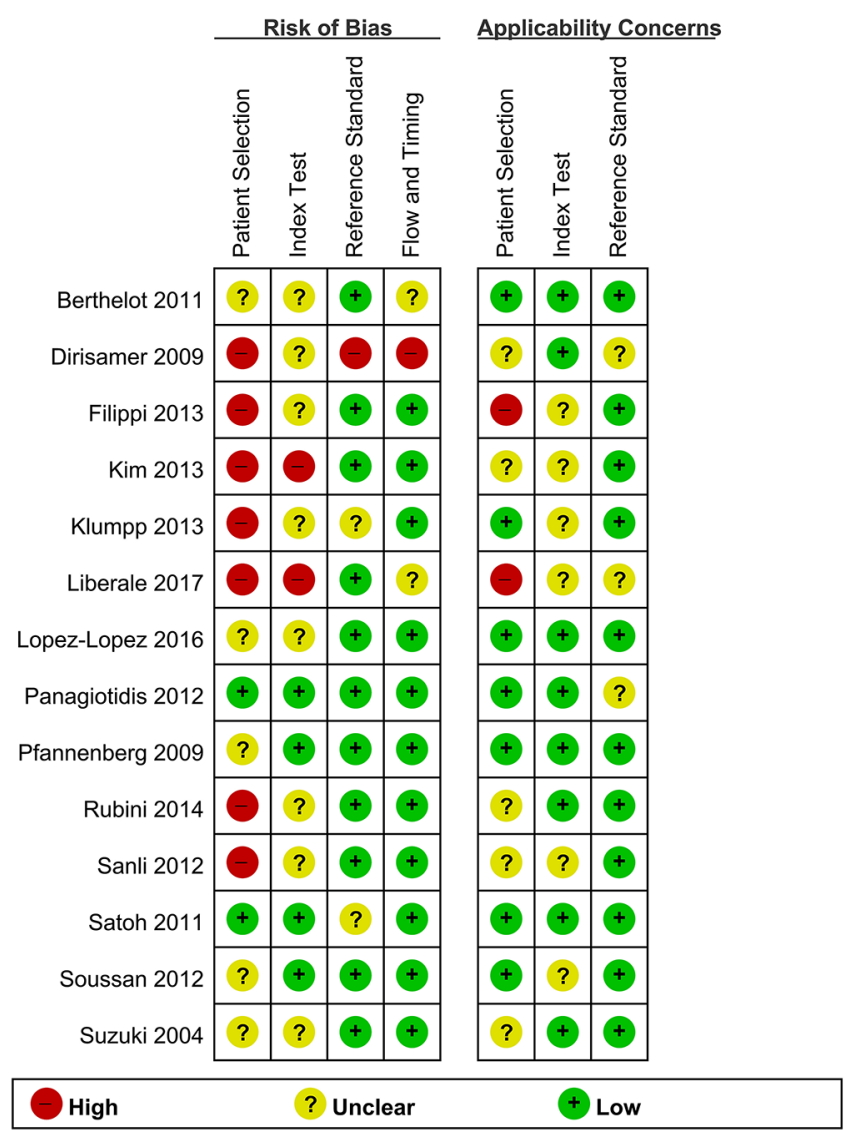


Figure 4. Forest plot of pooled sensitivity and specificity of ${ }^{18} \mathrm{~F}-\mathrm{FDG} \mathrm{PET} / \mathrm{CT}$ in the detection of PC. Summary of sensitivity and specificity of ${ }^{18} \mathrm{~F}-\mathrm{FDG}$ PET/CT was 0.87 [95\% Cl (0.77-0.93)] and 0.92 [95\% Cl (0.89-0.94)], respectively. ${ }^{18} \mathrm{~F}-\mathrm{FDG}$, fludeoxyglucose; PC, peritoneal carcinomatosis; PET, positron emission tomography.

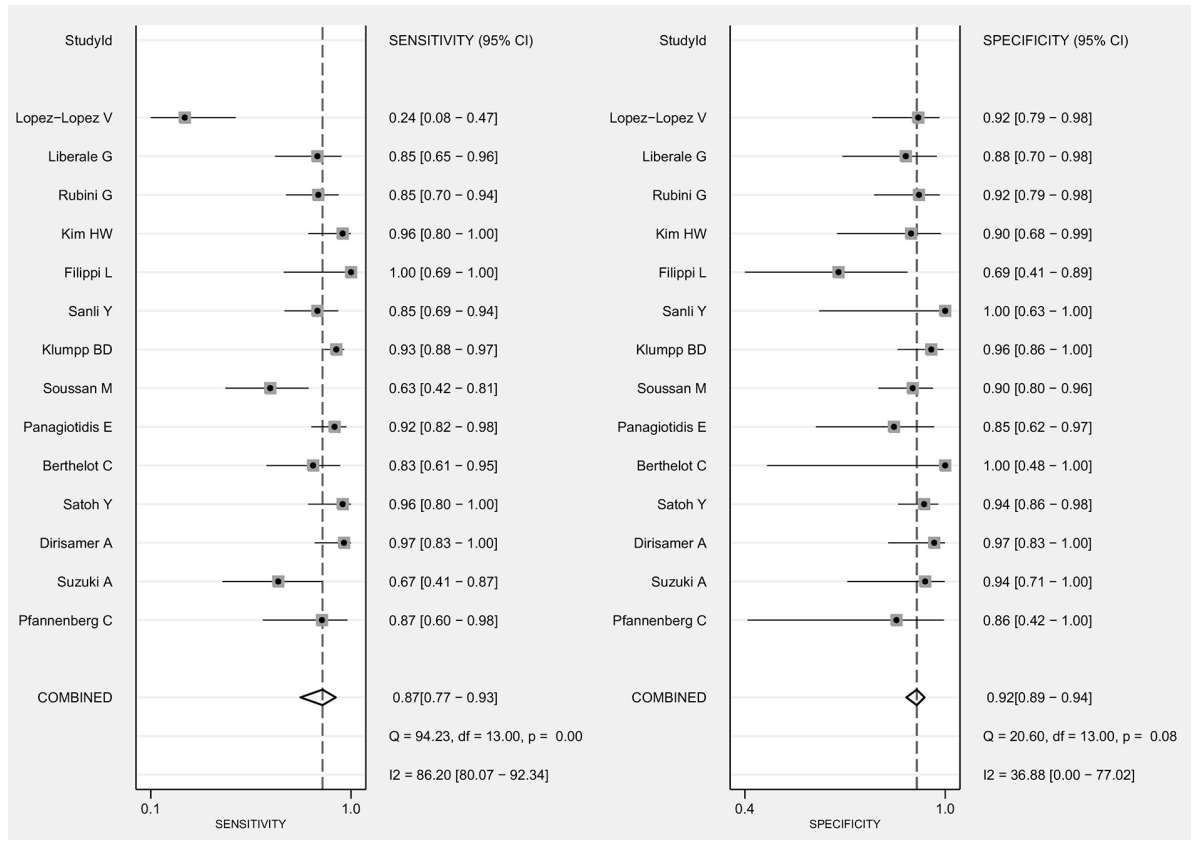

pooled specificity of 0.92 [95\% CI $(0.89-0.95)]$ without heterogeneity $\left(\chi^{2}=20.6, p=0.08\right)$. LR syntheses gave an overall LR+ of 10.4 [95\% CI (7.5-14.5)] and LR- of 0.14 (95\% CI; 0.08-0.26). The pooled DOR was 73 [95\% CI; (34-159)]. Forest plots of the sensitivity and specificity of ${ }^{18} \mathrm{~F}$-FDG PET/CT in the detection of $\mathrm{PC}$ are shown in Figure 4. Figure 5 shows hierarchical summary receiver operating characteristic curve and indicates that the areas under the curve was 0.92 [95\% CI (0.89-0.94)], indicating good diagnostic accuracy.

\section{Heterogeneity evaluation and meta-regression analysis}

Between-study heterogeneity was present for sensitivity among studies of ${ }^{18}$ F-FDG PET/CT for the detection of PC. A meta-regression analysis was performed to explore other sources of heterogeneity in the studies of ${ }^{18} \mathrm{~F}-\mathrm{FDG}$ PET/CT. Table 2 . lists the results of meta-regression analysis for identifying potential sources of heterogeneity. In univariate meta-regression analysis, publication year and cohort homogeneity were the potent sources of heterogeneity. However, in multivariate meta-regression, no definite variable was the source of the study heterogeneity.

\section{DISCUSSION}

PC has been considered to be a terminal stage of disease with a poor survival rate in the past and was treated only with palliative intention. ${ }^{40}$ Various imaging modalities have been used in the pre-operative assessment of tumour extent including CT, MRI as well as ${ }^{18} \mathrm{~F}$-FDG PET/CT. ${ }^{33,41}$ Several previous studies showed good results of MRI and PET/CT with advantages of functional and morphological tissue characterization. ${ }^{34}$ However, there is no universally accepted reference standard for imaging of PC. ${ }^{28}$
In this meta-analysis, the results reported that ${ }^{18} \mathrm{~F}-\mathrm{FDG}$ PET/ CT has excellent diagnostic accuracy in the detection of PC in various cancers, with an area under the ROC curve of 0.92 (95\% CI; 0.89-0.94). ${ }^{18}$ F-FDG PET/CT demonstrated a sensitivity of 0.87 (95\% CI; $0.77-0.93)$ and a specificity of 0.92 (95\% CI; 0.89-0.94). Panagiotidis E investigated the diagnostic accuracy of ${ }^{18} \mathrm{~F}-\mathrm{FDG}$ PET/CT for detection of PC. ${ }^{31}$ The sensitivity, specificity, positive-predictive value, negative-predictive value and

Figure 5. Hierarchical summary ROC curves for the detection of peritoneal carcinomatosis of ${ }^{18} \mathrm{~F}$-FDG PET/CT.

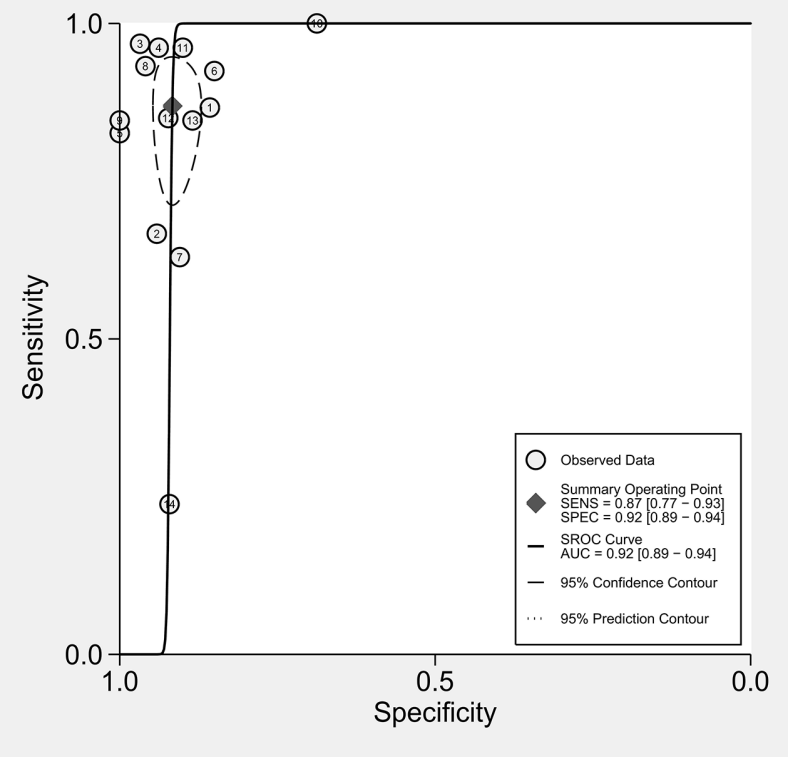


Table 2. Meta-regression analysis for identifying potential sources of heterogeneity in the diagnostic performance of ${ }^{18}$ F-FDG PET/ CT for the detection of peritoneal carcinomatosis

\begin{tabular}{|c|c|c|c|c|c|c|c|}
\hline \multirow[b]{2}{*}{ Variables } & \multirow[b]{2}{*}{ No of studies } & \multicolumn{4}{|c|}{ Univariate analysis } & \multicolumn{2}{|c|}{ Multivariate analysis } \\
\hline & & Sensitivity & $p$-value & Specificity & $p$-value & LRT $\chi 2$ & $p$-value \\
\hline \multicolumn{8}{|l|}{ Study location } \\
\hline Western countries & 11 & $0.86(0.76-0.95)$ & 0.40 & $0.91(0.88-0.94)$ & 0.10 & 0.99 & 0.61 \\
\hline others & 3 & $0.91(0.79-1.00)$ & & $0.93(0.89-0.98)$ & & & \\
\hline \multicolumn{8}{|l|}{ Study year } \\
\hline Before 2010 & 3 & $0.88(0.72-1.00)$ & 0.69 & $0.91(0.88-0.94)$ & 0.03 & 0.78 & 0.68 \\
\hline After or during 2010 & 11 & $0.87(0.78-0.96)$ & & $0.95(0.89-1.00)$ & & & \\
\hline \multicolumn{8}{|l|}{ Study design } \\
\hline Prospective & 1 & $0.93(0.78-1.00)$ & 0.86 & $0.85(0.69-1.00)$ & 0.06 & 1.42 & 0.49 \\
\hline Retrospective & 13 & $0.86(0.78-0.94)$ & & $0.92(0.89-0.95)$ & & & \\
\hline \multicolumn{8}{|l|}{ Image analysis } \\
\hline $\mathrm{PB}$ & 12 & $0.87(0.79-0.96)$ & 0.21 & $0.91(0.88-0.94)$ & 0.10 & 0.43 & 0.81 \\
\hline LB & 2 & $0.84(0.61-1.00)$ & & $0.93(0.88-0.98)$ & & & \\
\hline \multicolumn{8}{|l|}{ Cohort homogeneity } \\
\hline Homogenous & 6 & $0.84(0.70-0.98)$ & 0.21 & $0.89(0.84-0.94)$ & 0.00 & 2.31 & 0.31 \\
\hline Heterogeneous & 8 & $0.89(0.80-0.98)$ & & $0.93(0.90-0.96)$ & & & \\
\hline
\end{tabular}

${ }^{18}$ F-FDG, fludeoxyglucose; LRT, likelihood ratio test; PET, positron emission tomography; LB, lesion-based analysis; PB, patient-based analysis.

accuracy for diagnosing PC on a per-patient basis were 92.4, 85, 94.2, 81 and 91\%, respectively. Kim HW et al performed a retrospective analysis of 46 patients who underwent ${ }^{18} \mathrm{~F}-\mathrm{FDG}$ $\mathrm{PET} / \mathrm{CT}$ for the post-treatment surveillance of ovarian cancer. They demonstrated the sensitivity, specificity, positive-predictive value, negative-predictive value and accuracy of ${ }^{18} \mathrm{~F}-\mathrm{FDG}$ PET/ CT for PC to be $96.2,90,92.6,94.7$ and $93.5 \%$, respectively. ${ }^{36}$

However, some studies included in the current review reported low sensitivity of ${ }^{18}$ F-FDG PET/CT for the detection of PC. Lopez-Lopez et $\mathrm{al}^{39}$ evaluated the clinical usefulness of the results obtained with ${ }^{18} \mathrm{~F}$-FDG PET/CT in relation to CT in the pre-operative staging of patients with PC secondary to primary or recurrent ovarian cancer candidates to cytoreductive surgery and hyperthermic intraoperative intraperitoneal chemotherapy. They demonstrated the sensitivity, specificity, positive-predictive value and negative-predictive value of ${ }^{18} \mathrm{~F}-\mathrm{FDG}$ PET/CT for PC to be $24,93,66$ and $68 \%$.

Heterogeneity between studies could be an important source of bias. The included studies showed statistically significant heterogeneity in their estimates of sensitivity and specificity.
Possible explanation of this heterogeneity may be due to the diversity in methodological aspects between different studies and the basic clinical differences among the patients in the included studies (Table 1). However, according to the multivariate meta-regression analysis of the current study, no definite potent source of heterogeneity of this study was exist (Table 2).

\section{CONCLUSION}

${ }^{18}$ F-FDG PET/CT demonstrated good sensitivity and specificity for the detection of PC. Further large multicentre studies would be necessary to substantiate the diagnostic accuracy of ${ }^{18}$ F-FDG $\mathrm{PET} / \mathrm{CT}$ for the diagnosis of PC in various cancers.

\section{INFORMED CONSENT}

This study is meta-analysis of published articles; therefore IRB approval was waived and informed consent was also waived.

\section{FUNDING}

This research did not receive any specific grant from any funding agency in the public, commercial or not-for-profit sector.

\section{REFERENCES}

1. Glehen O, Osinsky D, Cotte E, Kwiatkowski F, Freyer G, Isaac S, et al. Intraperitoneal chemohyperthermia using a closed abdominal procedure and cytoreductive surgery for the treatment of peritoneal carcinomatosis: morbidity and mortality analysis of 216 consecutive procedures. Ann Surg Oncol 2003; 10:
863-9. doi: https://doi.org/10.1245/ASO. 2003.01.018

2. Glehen O, Gilly FN, Boutitie F, Bereder JM, Quenet F, Sideris L, et al. Toward curative 
treatment of peritoneal carcinomatosis from nonovarian origin by cytoreductive surgery combined with perioperative intraperitoneal chemotherapy: a multiinstitutional study of 1,290 patients. Cancer 2010; 116: 5608-18. doi: https://doi.org/10. $1002 /$ cncr.25356

3. Raue W, Tsilimparis N, Langelotz C, Rau B, Schwenk W, Hartmann J. Initial results after implementation of a multimodal treatment for peritoneal malignancies. Acta Chir Belg 2011; 111: 68-72. doi: https://doi.org/10. 1080/00015458.2011.11680709

4. Yang XJ, Huang CQ, Suo T, Mei LJ, Yang GL, Cheng FL, et al. Cytoreductive surgery and hyperthermic intraperitoneal chemotherapy improves survival of patients with peritoneal carcinomatosis from gastric cancer: final results of a phase III randomized clinical trial. Ann Surg Oncol 2011; 18: 1575-81. doi: https://doi.org/10.1245/s10434-011-1631-5

5. Deraco M, Nonaka D, Baratti D, Casali P, Rosai J, Younan R, et al. Prognostic analysis of clinicopathologic factors in 49 patients with diffuse malignant peritoneal mesothelioma treated with cytoreductive surgery and intraperitoneal hyperthermic perfusion. Ann Surg Oncol 2006; 13: 229-37. doi: https://doi.org/10.1245/ASO.2006.03.045

6. Deraco M, Casali P, Inglese MG, Baratti D, Pennacchioli E, Bertulli R, et al. Peritoneal mesothelioma treated by induction chemotherapy, cytoreductive surgery, and intraperitoneal hyperthermic perfusion. $J$ Surg Oncol 2003; 83: 147-53. doi: https://doi. org/10.1002/jso.10255

7. Fagotti A, Fanfani F, Rossitto C, Lorusso D, De Gaetano AM, Giordano A, et al. A treatment selection protocol for recurrent ovarian cancer patients: the role of FDG-PET/CT and staging laparoscopy. Oncology 2008; 75: 152-8. doi: https://doi. org/10.1159/000159266

8. Jacquet P, Jelinek JS, Steves MA, Sugarbaker PH. Evaluation of computed tomography in patients with peritoneal carcinomatosis. Cancer 1993; 72: 1631-6. doi: https://doi.org/10.1002/ 1097-0142(19930901)72:5\&lt;1631::AIDCNCR2820720523\&gt;3.0.CO;2-I

9. De Bree E, Koops W, Kröger R, van Ruth S, Witkamp AJ, Zoetmulder FA. Peritoneal carcinomatosis from colorectal or appendiceal origin: correlation of preoperative $\mathrm{CT}$ with intraoperative findings and evaluation of interobserver agreement. $J$ Surg Oncol 2004; 86: 64-73. doi: https://doi. org/10.1002/jso.20049

10. Yan TD, Haveric N, Carmignani CP, Chang D, Sugarbaker PH. Abdominal computed tomography scans in the selection of patients with malignant peritoneal mesothelioma for comprehensive treatment with cytoreductive surgery and perioperative intraperitoneal chemotherapy. Cancer 2005; 103: 839-49. doi: https://doi.org/10.1002/ cncr. 20836

11. Turlakow A, Yeung HW, Salmon AS, Macapinlac HA, Larson SM. Peritoneal carcinomatosis: role of ${ }^{18} \mathrm{~F}-\mathrm{FDG}$ PET. J Nucl Med 2003; 44: 1407-12.

12. Dromain C, Leboulleux S, Auperin A, Goere D, Malka D, Lumbroso J, et al. Staging of peritoneal carcinomatosis: enhanced CT vs. PET/CT. Abdom Imaging 2008; 33: 87-93. doi: https://doi.org/10.1007/s00261-0079211-7

13. Marin D, Catalano C, Baski M, Di Martino M, Geiger D, Di Giorgio A, et al. 64-section multi-detector row $\mathrm{CT}$ in the preoperative diagnosis of peritoneal carcinomatosis: correlation with histopathological findings. Abdom Imaging 2010; 35: 694-700. doi: https://doi.org/10. 1007/s00261-008-9464-9

14. Coakley FV, Choi PH, Gougoutas CA, Pothuri B, Venkatraman E, Chi D, et al. Peritoneal metastases: detection with spiral CT in patients with ovarian cancer. Radiology 2002; 223: 495-9. doi: https://doi.org/10. 1148/radiol.2232011081

15. Cistaro A, Niccoli Asabella A, Coppolino P, Quartuccio N, Altini C, Cucinotta M, et al. Diagnostic and prognostic value of ${ }^{18} \mathrm{~F}$-FDG PET/CT in comparison with morphological imaging in primary adrenal gland malignancies - a multicenter experience. Hell J Nucl Med 2015; 18: 97-102. doi: https://doi. org/10.1967/s002449910202

16. Quartuccio N, Treglia G, Salsano M, Mattoli MV, Muoio B, Piccardo A, et al. The role of Fluorine-18-Fluorodeoxyglucose positron emission tomography in staging and restaging of patients with osteosarcoma. Radiol Oncol 2013; 47: 97-102. doi: https:// doi.org/10.2478/raon-2013-0017

17. Moher D, Liberati A, Tetzlaff J, Altman DG, Group P.PRISMA Group Preferred reporting items for systematic reviews and metaanalyses: the PRISMA statement. PLoS Med 2009; 6: e1000097. doi: https://doi.org/10. 1371/journal.pmed.1000097

18. Whiting PF, Rutjes AW, Westwood ME, Mallett S, Deeks JJ, Reitsma JB, et al. QUADAS-2: a revised tool for the quality assessment of diagnostic accuracy studies. Ann Intern Med 2011; 155: 529-36. doi: https://doi.org/10.7326/0003-4819-155-8201110180-00009

19. Glas AS, Lijmer JG, Prins MH, Bonsel GJ, Bossuyt PM. The diagnostic odds ratio: a single indicator of test performance. J Clin
Epidemiol 2003; 56: 1129-35. doi: https://doi. org/10.1016/S0895-4356(03)00177-X

20. Thompson SG. Why sources of heterogeneity in meta-analysis should be investigated. $B M J$ 1994; 309: 1351-5. doi: https://doi.org/10. 1136/bmj.309.6965.1351

21. Deeks JJ, Macaskill P, Irwig L. The performance of tests of publication bias and other sample size effects in systematic reviews of diagnostic test accuracy was assessed. J Clin Epidemiol 2005; 58: 882-93. doi: https://doi.org/10.1016/j.jclinepi.2005. 01.016

22. Reitsma JB, Glas AS, Rutjes AW, Scholten RJ, Bossuyt PM, Zwinderman AH. Bivariate analysis of sensitivity and specificity produces informative summary measures in diagnostic reviews. J Clin Epidemiol 2005; 58: 982-90. doi: https://doi.org/10.1016/j. jclinepi.2005.02.022

23. Hamza TH, van Houwelingen HC, Stijnen T. The binomial distribution of meta-analysis was preferred to model within-study variability. J Clin Epidemiol 2008; 61: 41-51. doi: https://doi.org/10.1016/j.jclinepi.2007. 03.016

24. Rutter CM, Gatsonis CA. A hierarchical regression approach to meta-analysis of diagnostic test accuracy evaluations. Stat Med 2001; 20: 2865-84. doi: https://doi.org/ 10.1002/sim.942

25. Lijmer JG, Mol BW, Heisterkamp S, Bonsel GJ, Prins MH, van der Meulen JH, et al. Empirical evidence of design-related bias in studies of diagnostic tests. JAMA 1999; 282: 1061-6. doi: https://doi.org/10. 1001/jama.282.11.1061

26. Pfannenberg C, Königsrainer I, Aschoff P, Oksüz MO, Zieker D, Beckert $\mathrm{S}$, et al. ${ }^{18} \mathrm{~F}$-FDG-PET/CT to select patients with peritoneal carcinomatosis for cytoreductive surgery and hyperthermic intraperitoneal chemotherapy. Ann Surg Oncol 2009; 16: 1295-303. doi: https://doi. org/10.1245/s10434-009-0387-7

27. Suzuki A, Kawano T, Takahashi N, Lee J, Nakagami Y, Miyagi E, et al. Value of 18F-FDG PET in the detection of peritoneal carcinomatosis. Eur J Nucl Med Mol Imaging 2004; 31: 1413-20. doi: https://doi.org/10. 1007/s00259-004-1577-y

28. Dirisamer A, Schima W, Heinisch M, Weber M, Lehner HP, Haller J, et al. Detection of histologically proven peritoneal carcinomatosis with fused 18F-FDG-PET/ MDCT. Eur J Radiol 2009; 69: 536-41. doi: https://doi.org/10.1016/j.ejrad.2007.11.032

29. Satoh Y, Ichikawa T, Motosugi U, Kimura K, Sou H, Sano K, et al. Diagnosis of peritoneal dissemination: comparison of 18F-FDG PET/CT, diffusion-weighted MRI, 
and contrast-enhanced MDCT. AJR Am J Roentgenol 2011; 196: 447-53. doi: https:// doi.org/10.2214/AJR.10.4687

30. Berthelot C, Morel O, Girault S, Verrièle V, Poirier AL, Moroch J, et al. Use of FDG$\mathrm{PET} / \mathrm{CT}$ for peritoneal carcinomatosis before hyperthermic intraperitoneal chemotherapy. Nucl Med Commun 2011; 32: 23-9. doi: https://doi.org/10.1097/MNM. 0b013e328340e 730

31. Panagiotidis E, Datseris IE, Exarhos D, Skilakaki M, Skoura E, Bamias A. High incidence of peritoneal implants in recurrence of intra-abdominal cancer revealed by $18 \mathrm{~F}-\mathrm{FDG}$ PET/CT in patients with increased tumor markers and negative findings on conventional imaging. Nucl Med Commun 2012; 33: 431-8. doi: https://doi. org/10.1097/MNM.0b013e3283506ae1

32. Soussan M, Des Guetz G, Barrau V, Aflalo-Hazan V, Pop G, Mehanna Z, et al. Comparison of FDG-PET/CT and MR with diffusion-weighted imaging for assessing peritoneal carcinomatosis from gastrointestinal malignancy. Eur Radiol 2012; 22: 1479-87. doi: https://doi.org/10.1007/ s00330-012-2397-2

33. Klumpp BD, Schwenzer N, Aschoff P, Miller S, Kramer U, Claussen CD, et al. Preoperative assessment of peritoneal carcinomatosis: intraindividual comparison of 18F-FDG PET/CT and MRI. Abdom
Imaging 2013; 38: 64-71. doi: https://doi.org/ 10.1007/s00261-012-9881-7

34. Sanli Y, Turkmen C, Bakir B, Iyibozkurt C, Ozel S, Has D, et al. Diagnostic value of PET/ $\mathrm{CT}$ is similar to that of conventional MRI and even better for detecting small peritoneal implants in patients with recurrent ovarian cancer. Nucl Med Commun 2012; 33: 509-15. doi: https://doi.org/10.1097/MNM. ob013e32834fc5bf

35. Filippi L, D'Arienzo M, Scopinaro F, Salvatori R, Bagni O. Usefulness of dual-time point imaging after carbonated water for the fluorodeoxyglucose positron emission imaging of peritoneal carcinomatosis in colon cancer. Cancer Biother Radiopharm 2013; 28: 29-33. doi: https://doi.org/10.1089/ cbr.2012.1179

36. Kim HW, Won KS, Zeon SK, Ahn BC, Gayed IW. Peritoneal carcinomatosis in patients with ovarian cancer: enhanced CT versus 18F-FDG PET/CT. Clin Nucl Med 2013; 38: 93-7. doi: https://doi.org/10.1097/ RLU.0b013e31826390ec

37. Rubini G, Altini C, Notaristefano A, Merenda $\mathrm{N}$, Rubini $\mathrm{D}$, Ianora AA, et al. Role of 18F-FDG PET/CT in diagnosing peritoneal carcinomatosis in the restaging of patient with ovarian cancer as compared to contrast enhanced CT and tumor marker Ca-125. Rev Esp Med Nucl Imagen Mol 2014; 33: 22-7. doi: https://doi.org/10.1016/j.remn.2013.06.008
38. Liberale G, Lecocq C, Garcia C, Muylle K, Covas A, Deleporte A, et al. Accuracy of FDG-PET/CT in colorectal peritoneal carcinomatosis: potential tool for evaluation of chemotherapeutic response. Anticancer Res 2017; 37: 929-34. doi: https:// doi.org/10.21873/anticanres.11401

39. Lopez-Lopez V, Cascales-Campos PA, Gil J, Frutos L, Andrade RJ, Fuster-Quiñonero M, et al. Use of ${ }^{18} \mathrm{~F}$-FDG PET/CT in the preoperative evaluation of patients diagnosed with peritoneal carcinomatosis of ovarian origin, candidates to cytoreduction and hipec. A pending issue. Eur J Radiol 2016; 85: 1824-8. doi: https://doi.org/10.1016/j.ejrad. 2016.08.006

40. Tabrizian P, Shrager B, Jibara G, Yang MJ, Romanoff A, Hiotis S, et al. Cytoreductive surgery and hyperthermic intraperitoneal chemotherapy for peritoneal carcinomatosis: outcomes from a single tertiary institution. J Gastrointest Surg 2014; 18: 1024-31. doi: https://doi.org/10.1007/ s11605-014-2477-5

41. Funicelli L, Travaini LL, Landoni F, Trifirò G, Bonello L, Bellomi M. Peritoneal carcinomatosis from ovarian cancer: the role of $\mathrm{CT}$ and $\left[{ }^{18} \mathrm{~F}\right]$ FDG-PET/CT. Abdom Imaging 2010; 35: 701-7. doi: https://doi.org/ $10.1007 / \mathrm{s} 00261-009-9578-8$ 